УАK $341.1 / .8$

ББК 67.412 .1

DOI 10.22394/1682-2358-2021-4-12-22

N.A. Bylinskaya, postgraduate student of the Scientific and Scientific-Pedagogical Staff Training Faculty, Management Academy of the Ministry of Interior of Russia

\section{EUROPEAN COURT OF HUMAN RIGHTS PRACTICES \\ IN THE RUSSIAN FEDERATION CITIZENS' RIGHTS AND FREEDOMS PROTECTION MECHANISM}

The European Court of Human Rights activities in the field of the Russian Federation citizens' rights and freedoms protection are analyzed. Statistical analysis of the quantitative indicator of complaints considered by the Court, filed by Russian citizens about violations of their rights and freedoms for the period 1959-2020 is carried out. The conclusion is made about the need to find effective ways of interaction between national and international bodies competent in the field of citizens' rights and freedoms protection.

Key words and word-combinations: Convention on Human Rights, citizens' rights and freedoms, European Court of Human Rights, Constitutional Court.
Н.А. Бъиинская, адъюнкт факультета подготовки научньхх и научно-педагогиеских кадров Академии упраљления МВА России (етаil: natali.bylinskaya@mail.ru)

\section{$\triangle$ АЯТЕ $\Lambda$ НОСТЬ ЕВРОПЕЙСКОГО СУАА ПО ПРАВАМ ЧЕ $А$ ОЕКА В МЕХАНИЗМЕ ЗАЩИТЫ ПРАВ И СВОБОА ГРАЖААН РОССИЙСКОЙ ФЕАЕРАЦИИ}

\footnotetext{
Аннотаиия. Анализируется деятельность Европейского суда по правам человека в области защиты прав и свобод граждан Российской Федерации. Проведен статистический анализ количественных показателей рассмотренных Судом жалоб, поданных гражданами России, о нарушении их прав и свобод в период 19592020 гг. Делается вывод о необходимости поиска эффективных путей взаимодействия между национальными и международными органами, компетентными в сфере защиты прав и свобод граждан.

Ключевые слова и словосочетания: Конвенция о правах человека, права и свободы граждан, Европейский суд по правам человека, Конституционный Суд РФ.

Po к числу стран, из которых в Европейский суА по правам человека (ЕСПЧ) регулярно поступает Аоминируюшее количество жалоб. К таким странам также относятся Турция, Украина, Румыния и Италия, хотя в отАичие от них
} 
территориальные масштабы России определяют специфический характер проблем в этой сфере [1] .

ЕСПЧ - искАючительный механизм защиты права Амя рассмотрения нарушений конвенционных норм и организации правового контроля за соблюдением обязательств государств - участников Совета Европы [2, с. 128]. Число судей, явмяющихся членами ЕСПЧ, соответствует числу стран - участников Конвенции о защите прав человека и основных свобод. Большое количество судей (порядка 35 000) преАставляет собой оправданную меру, позволяющую СУАу в настоящее время справцяться с огромным потоком поступающих дел.

С момента учреждения Суда государства - чкены Совета Европы приняли рял протоколов к Конвенции, направленных на совершенствование и укрепление надзорного механизма Суда. Так, в 1998 г. протокоц № 11 [3] реформировац изначальную (Авухуровневую) структуру ЕСПЧ - комиссию и суА по правам человека, модернизировав ее в еАиный постоянный СУА, что позволицо облегчить проџеАуру подачи жалобы, минуя комиссию, наделенную функщией фимьтрации подаваемых жалоб. Отметим, что до 1998 г. проведение заседаний было ограничено - несколько Аней в месяц.

Важным этапом реформирования в свете принятия и вступления в силу в 2010 г. Протокола № 14 [4] было решение проблемы существенного увеличения количества заявлений и отставания Суда в их рассмотрении. Протоколом устанавливался новый критерий допустимости - наличие «сушественного недостатка» дия заявителя, а также новый срок полномочий судей, не подлежащий возобновлению, - Ао Аевяти мет.

С 2010 г. бымо созвано нескомько конференций высокого уровня, касающихся вопросов организации системы будущего Суда, целью которых являлось определение путей обеспечения Аолгосрочной эффективности конвенџионной системы. Продуктивные итоги провеАенных конференций послужили индикатором принятия протоколов № 15 и 16 к Конвенции. Так, принятый в 2013 г. Протокол № 15 [5] закрепим вкмючение в преамбулу Конвенции доктрины свободы усмотрения, а также принџипа субсидиарности, что способствовало сокращению срока обращения с жалобой в ЕСПЧ Ао четырех месяцев (ранее составмявший шесть месяџев). Протокол № 15 вступиц в силу после его подписания и последуюшей ратификации всеми государствами-участниками.

В целях обеспечения и защиты прав и свобод граждан государствучастников, а также Аальнейшего реформирования защитного ме- 
ханизма ЕСПЧ с 2018 г. высшим судам и трибуналам государствучастников разрешается обрашаться в СуА с просьбой о вынесении консультативных заключений по принципиальным вопросам, затрагивающим спорные моменты при толковании (применении) прав, свобод Конвенции [6], что позволицо вывести на новый уровень имплементацию конвенционных норм на внутригосударственном уровне.

Не вызывает сомнения, что роль Европейского суда по правам человека весьма значительна в вопросах, касающихся защиты прав и свобоА человека. Осознавая это и руководствуясь необходимостью повышения своей эффективности, ЕСПЧ быха разработана экспериментальная процедура принятия решений Аля удовметворения массового притока заявлений по аналогичным вопросам, среди которых встречались и «системные или структурные проблемы». Повышению коэффициента полезного действия в деятельности СУАа способствовало введение "помитики приоритета», целью которой явцяется учет срочности и важности вопросов, поднимаемых при принятии решений о порядке рассмотрения дем.

В соответствии со ст. 46 Конвенции решения ЕСПЧ обладают слеАующими свойствами:

окончательны и императивны Амя исполнения странами-участниками; направцяются в Комитет министров Совета Европы (KMCE) надзорный орган, следящий за исполнением окончательного постановления;

КМСЕ (по мнению 2/3 представителей) передает дело в СУА Амя принятия решения о толковании (в случае возникновения спорных ситуаций при толковании решений);

в связи с неисполнением государством-участником судебного решения КМСЕ надемен правом офиџиального уведомления этой стороны и по решению 2/3 представителей - последующей передачей в Суд вопроса о возможном нарушении данной стороной своих обязательств, указанных в пункте 1 настоящей статьи;

по рассмотрении вопроса о нарушении государством-участником п. 1 настояшей статьи дело передается в КМСЕ, гАе принимается одно из следующих решений:

- в случае признания Судом нарушения КМСЕ рассматривает варианты принятия мер к государству-участнику;

- в случае отсутствия нарушения со стороны государства-участника КМСЕ откладывает рассмотрение дела [7].

Как отмечалось, решения Суда явцяются обязательными. Установив 
факт нарушения, страна-участник, допустившая нарушение, обязана исполнить принятое решение, приняв необходимые меры для обеспечения неАопущения подобных нарушений и устранения послеАствий Аля жертвы. Помимо прочего, СуА вправе обязать государство выплатить заявителю денежную сумму в качестве компенсаџии за причиненный вреА и (или) применить конкретные меры (освобождение заявителя, если он (она) находится поА стражей, восстановление контактов с ребенком заявителя, преАоставление ему (е)й вида на жительство).

KMCЕ, упомномоченный осуществАять мониторингприменения решений Суда, помогает государствам-участникам определить необходимые меры и найти варианты исполнения в случае возникновения проблем при исполнении решения. В рамках своих полномочий КМСЕ производит оценку эффективности мер, принятых в отношении заявителя и иных миц, которые могут оказаться в такой жке ситуации.

Отметим, что за 2020 г. в ЕСПЧ поступили почти 62000 обращений о рассмотрении жкалоб от граждан государств - чиенов Совета Европы, из которых 13650 (22\% от общего числа поступивших заявок) поданы против России и ожкидают рассмотрения [8] .

Россия является мидером среди стран, выступающих ответчиком при обжаловании несправедливых и незаконных, по мнению заявитемей, решений национальных судов. С каждым годом количество жалоб, подаваемых против Российской Федераџии, растет в геометрической прогрессии. Это обусловлено рядом причин: во-первых, ЕСПЧ имеет высокую репутацию; во-вторых, решение ЕСПЧ - последняя надежАа на справедливость. Изучение практики ЕСПЧ показывает, что им принимаются вполне мотивированные и взвешенные решения, к тому же Страсбургский суд в действительности обладает независимостью и беспристрастностью - основополагающими качествами судебного органа.

За 61 гол процессуальной деятельности (с момента своего основания в 1959 г. по 2020 г.) ЕСПЧ бымо вынесено 23406 судебных решений, более $1 / 3$ которых затронули интересы Италии (2427), Российской Федерации (2884) и Турџии (3742). Судом с 1959 г. установлено по меньшей мере одно нарушение конвенционных положений, Аопушенное государством-ответчиком в $84 \%$ вынесенных решений. Только по итогам 2020 г. Судом установлено допущение нарушений Конвенции со стороны Российской Федерации в 87\% рассмотренных жалоб [9] (таблица). 
Категории дел, рассмотренных ЕСПЧ в период 1959-2020 гг., в которых стороной-ответчиком выступала Российская Федераџия [10]

\begin{tabular}{|c|c|c|}
\hline $\begin{array}{l}\text { № } \\
\Pi / \Pi\end{array}$ & Категория дел, рассмотренных ЕСПЧ & $\begin{array}{c}\text { Количество дел, в которых } \\
\text { стороной-ответчиком выступала } \\
\text { Российская Федерация }\end{array}$ \\
\hline 1 & Право на жизнь & 330 \\
\hline 2 & $\begin{array}{l}\text { Отсутствие эффективного } \\
\text { расследования }\end{array}$ & 373 \\
\hline 3 & Запрещение пыток & 76 \\
\hline 4 & $\begin{array}{l}\text { Бесчеловечное или унижающее } \\
\text { достоинство обращение }\end{array}$ & 916 \\
\hline 5 & Отсутствие эффективного расследования & 241 \\
\hline 6 & Условные нарушения & 40 \\
\hline 7 & $\begin{array}{l}\text { Запрещение рабства / } \\
\text { принудительного труда }\end{array}$ & 1 \\
\hline 8 & $\begin{array}{l}\text { Право на свободу и личную } \\
\text { неприкосновенность }\end{array}$ & 1203 \\
\hline 9 & $\begin{array}{l}\text { Право на справедливое судебное } \\
\text { разбирательство }\end{array}$ & 935 \\
\hline 10 & Продолжительность разбирательства & 207 \\
\hline 11 & Не исполнение & 158 \\
\hline 12 & $\begin{array}{l}\text { Наказание исключительно } \\
\text { на основании закона }\end{array}$ & 3 \\
\hline 13 & $\begin{array}{l}\text { Право на уважение частной } \\
\text { и семейной жизни }\end{array}$ & 244 \\
\hline 14 & $\begin{array}{l}\text { Свобода мысли, совести } \\
\text { и вероисповедания }\end{array}$ & 11 \\
\hline 15 & Свобода слова & 95 \\
\hline 16 & Свобода собраний и ассоциаций & 68 \\
\hline 17 & Право на вступление в брак & - \\
\hline 18 & $\begin{array}{l}\text { Право на эффективное средство } \\
\text { правовой защиты }\end{array}$ & 660 \\
\hline 19 & Запрещение дискриминации & 22 \\
\hline 20 & Защита собственности & 671 \\
\hline 21 & Право на образование & 3 \\
\hline 22 & Прова на свободные выборы & 6 \\
\hline 23 & $\begin{array}{l}\text { Право не быть дважды судимым } \\
\text { или наказанным }\end{array}$ & 7 \\
\hline 24 & Другие статьи Конвенции & 149 \\
\hline
\end{tabular}

16 Bulletin of the Volga Region Institute of Administration • 2021. Vol. 21. № 4 
Ознакомившись с решениями ЕСПЧ, нетрудно убедиться, что при их вынесении СУА руководствуется положениями конвенционных норм и протоколами к ним, определяет наличие (отсутствие) нарушений со стороны российских властей. В отличие от решений Конституционного Суда РФ (КС РФ), в которых прямо признается несоответствие отдельных положений федеральных законов Конституџии, судебные решения ЕСПЧ обычно констатируют проблему и Аают оџенку национальному законодательству и правоприменительной практике.

Первый председатель КС РФ В.А. Зорькин отмечает: «Конституционный СуА неоднократно подчеркивал в своих решениях значение конститущионного права каждого обращаться в соответствии с международными договорами России в межкосударственные органы по защите прав и свобод человека, если исчерпаны все имеющиеся внутригосуАарственные средства правовой защиты» [11] .

Европейский суА, по мнению многих гражАан, является «последней инстанщией», способной принять законное, обоснованное и справедцивое решение о восстановцении нарушенных прав, ввиду пассивности внутригосударственных среАств правовой защиты. По состоянию на 31 декабря 2020 г. против России подано 185 жкалоб, что явцяется наибольшим статистическим показателем.

ОАнако необходимо отметить, что к функциям ЕСПЧ не относится замена органов власти, отвечающих за обеспечение прав, свобод человека и гражданина. Соответственно, на территории конкретного государства правоприменительная практика должна формироваться именно полномочными национацьными органами, а не ЕСПЧ.

10 октября 2003 г. Пиенум Верховного Суаа РФ (ВС РФ) вынес постановление, согласно которому «...исполнение судебных решений, затрагивающих Российскую Федерацию, предполагает при необходимости обязательство правительства принимать индивидуальные меры, направленные на устранение нарушений прав человека, закрепленных в Конвенции, и послеАствий этих нарушений для заявителя, а также общие меры по предотвращению повторения таких нарушений. Суды АОлжны действовать в пределах своей юрисдикции таким образом, чтобы выполнять обязательства правительства, вытекающие из участия Российской Федерации в Конвенции о защите прав человека и основных свобод” [12] .

При этом А.И. Ковлер подчеркивает, что, невзирая на многолетнюю правую позицию ВС РФ, неоднократно признающую приоритетность межАународных договоренностей и решений ЕСПЧ, он все же стал акцентировать внимание на необходимости адекватного их выполнения 
(постановление Пиенума Верховного Суда Российской Федерации от 27 июня 2013 г. № 21 г. [13] ) [14] .

Тем не менее с 2011 г. в цемях исполнения постановмений Суда ведется активная работа по улучшению российского законодательства: федеральные исполнительные органы пролонгируют деятельность по подготовке законопроектов в пределах исполнения постановлений: от 18 апреля 2013 г. по делу «Агеевы против Российской Федерации (Ageyevy v. Russia)», жамоба № 7075/10; от 18 сентября 2014 г. по Аелу Аванесян против Российской Федерации (Avanesyan v. Russia), жамоба № 41152/06; от 16 июмя 2015 г. по делу Назаренко против Российской Федерации (Nazarenko v. Russia), жамоба № 39438/13; от 19 ноября 2015 г. по делу Михайлова против Российской Федерации (Mikhailova v. Russia), жалоба № 46 998/08, объединенных в группу дел Роман Захаров (Roman Zakharov), Карелин (Karelin).

Вместе с тем внесение изменений в отечественную нормативноправовую базу, индикатором которых стали решения ЕСПЧ, положительно повлияли на защиту прав и интересов наименее защищенных категорий российских граждан. К примеру, в рамках исполнения постановления Суда от 27 марта 2008 г. по делу «Штукатуров против Российской Федерации» (Shtukaturov v. Russia), жалоба № 44009/05 [15] принят закон от 30 декабря 2012 г. № 302-Ф3 [16], позволивший осушествлять наиболее полную защиту прав и интересов гражАан, страдающих психическими расстройствами.

Таким образом, по состоянию на август 2020 г. на рассмотрении в Государственной Ауме находятся восемь законопроектов, подготовленных с учетом правовых позиций Страсбургского суда по декам:

группа дел «Гарабаев (Garabayev), Ракевич (Rakevich), Ваньян (Vanyan), Ким (Kim), Свинаренко и Сляднев» (Svinarenko and Slyadnev);

постановления:

- от 19 февраля 2013 г. по делу «Ефимова против Российской ФеАерации» (Yefimova v. Russia), жалоба № 39786 / 09;

- от 23 марта 2016 г. по делу «Блохин против Российской Федерации» (Blokhin v. Russia), жамоба № 47 152/06;

- от 14 февраля 2017 г. по делу «Амланазарова против Российской Федерации» (Allanazarova v. Russia), жамоба № 46721 / 15) [17] .

В период с 2011 по 2019 г. Российская Федераџия внесла немало изменений в законодательные акты страны, но в рамках исполнения решений Страсбургского суда [18] принятых мер явно недостаточно Аля обеспечения защиты прав и свобод российских гражАан, так как число ежегодно подаваемых жалоб остается весьма существенным. 
Не наблюдается и активного законотворческого процесса в сфере защиты прав, свобод и интересов граждан России. Решения ЕСПЧ не исполняются годами, проџесс принятия изменений и дополнений во внутригосударственную нормативно-правовую базу затянут часто на неограниченный срок. Россия продолжает занимать мидирующие позиџии и по числу неисполненных решений Страсбургского суда.

Проблемы исполнения решений ЕСПЧ сводятся к нескольким причинам.

ОАной из них, по мнению исследователей, является слишком быстрый процесс имплементации конвенционных норм посме их ратификации в российскую нормативно-правовую базу, что не позволяет на Аолжном уровне усовершенствовать российское законодательство в столь короткие сроки и приводит к недостаткам и комлизиям при их применении внутригосударственными органами власти [19, p. 21-44].

Еще одна существенная причина - различие правовых систем. СуАебная практика ЕСПЧ, конвенџионные положения - яркий пример норм, содержащих прецедентное толкование. Решения Страсбургского суда основаны на прецедентном праве и представляют собой отличительную черту англосаксонской системы права. ОАнако прецедентное толкование норм de јure неприменимо в процессе правового регулирования в России, относящейся к романо-германской (континентальной) системе права. При этом, как отмечают А.С. Велиева и М.В. Пресняков, сам по себе прецедент ЕСПЧ не явмяется основанием Амя его безоговорочного применения. Они подчеркивают, что прецедент как источник права характерен дмя стран англосаксонского права, которые руководствуются правицом «stare decisis» (буквально - стоять на решенном). ОАнако, на взгляд специалистов в Аанной области, и в странах прецедентного права приоритет отдается национальным прецедентам, а не практике ЕСПЧ [20, с. 21].

Подобная ситуация возникла и в России в 2015 г., когда, не имея закона, регламентируюшего исполнение решений ЕСПЧ, но при этом признавая приоритетность международных договоренностей в сфере защиты прав и свобод человека и гражданина (ч. 1 ст. 17 Конституции России, постановление КС РФ от 5 феврамя 2007 г. № 2-П [21] ), Российская Федерация вступила в «противодействие» с постановлением Страсбургского суда, противоречашим действуюшему внутригосударственному законодательству. ОАнако с целью исполнения межАунароАных обязательств Россия предпочла найти компромиссное решение Суда, чем отказаться от него в категоричной форме.

Впоследствии в Федеральный конституционный закон «О Конституционном Суде Российской Федерации» [22] были внесены изменения, 
наделившие Конституционный Суд России полномочиями проверять возможность исполнения решений межгосударственных органов по правам человека в случае возникновения сомнений в соответствии толкования положений межАународного договора, содержащихся в этом решении, Конституции РФ. В нем говорится не о противоречии межАу межАународным договором и Конституцией РФ, а о «разногласии толкований» этих положений наднациональными и национальными органами [20, с. 11-12].

Аостигнуть предотвращения подобного «разногласия толкований», по нашему мнению, возможно посредствам коммуникации межАу национальными и межАународными судебными органами. Это позволит не только обеспечить выполнение Россией решений Суда, находить компромиссы при их выполнении, но окажет положительное влияние и на законотворческую и правоприменительную деятельность национальной судебной системы. Безусловно, коммуникация наднациональных и внутригосударственных судов позволяет более эффективно защищать права и свободы мюдей, нежкели желание каждой из сторон отстоять свою точку зрения [23, с. 52].

Итак, ратификация конвенционных положений, с одной стороны, позволика вывести российское законодательство в сфере защиты прав, свобод и интересов граждан на новый уровень, а с Аругой стороны, не способна обеспечить продуктивное «сотрудничество» Конвенции и норм отечественного правоприменения. Отсутствие правового регулирования в данной сфере посреАством применения обязательных юридических норм привело к законодательному пробелу: не регламентирован порядок исполнения решений ЕСПЧ, отсутствуют сроки разработки и внесения в Государственную Ауму РФ законопроектов, направленных на реализацию решений СуАа. Способом его преодоления является разработка законопроекта регламента по исполнению решений ЕСПЧ Российской ФеАерацией с последующим его принятием.

Аанные обстоятельства представцяют собой юридические комиизии, препятствующие формированию правотворческой и правоприменительной деятельности в сфере защиты прав и свобод человека и гражданина на территории Российской Федерации, что пагубно сказывается на их обеспечении и защите, а также свидетельствует о несовершенстве проџесса интеграции России в конвенџионную систему. Такое положение вещей затрудняет исполнение Россией обязательств, взятых на себя в рамках ратификации Конвенции. 


\section{Библиографический список}

1. Судья от Российской Федерации в Европейском суде по правам человека: решения ЕСПЧ обязательны для исполнения, но не все так просто. URL: https://www. interfax.ru/interview/689399

2. Левченко И.В. Деятельность ЕСПЧ и конституционные приоритеты положения личности в Российской Федерации // Проблемы организации органов государственной власти и местного самоуправления: история, теория, практика и перспективы: материалы междунар. научно-практической конференции (Иркутск, 4-5 апреля 2015 г.). Иркутск, 2015. С. 126-133.

3. Протокол № 11 к Конвенции о защите прав человека и основных свобод от 11 мая 1994 г. // СЗ РФ. 1998. № 44. Ст. 5400.

4. Протокол № 14 к Конвенции о защите прав человека и основных свобод от 13 мая 2004 г. // Бюллетень международных договоров. 2010. № 4.

5. Протокол № 15 к Конвенции о защите прав человека и основных свобод от 24 июня 2013 г. URL: https://www.coe.int/ru/web/conventions/full-list//conventions/treaty/213

6. Протокол № 16 к Конвенции о защите прав человека и основных свобод от 2 октября 2013 г. URL: https://www.coe.int/ru/web/conventions/full-list/-/conventions/ treaty $/ 214$

7. Конвенция о защите прав человека и основных свобод от 4 ноября 1950 г. // С3 РФ. 2001. № 2. Ст. 163.

8. ECHR - Analysis of Statistics 2020. URL: https://www.echr.coe.int/Documents/ Stats_analysis_2020_ENG.pdf

9. This Overview presents various comparative statistics concerning judgments and violations for the period 1959-2020. URL: https://www.echr.coe.int/Pages/home. asp $\mathrm{x}$ p $=$ reports/factsfigures $\& \mathrm{c}=$

10. Violations by Article \& by State 1959-2020. URL: https://www.echr.coe.int/Documents/Stats_violation_1959_2020_ENG.pdf

11. Предварительные итоги деятельности Конституционного Суда РФ на пороге 15-летия: интернет-интервью с В.Д. Зорькиным, председателем Конституционного Суда РФ. URL: http://www.consultant.ru/law/interview/zorkin/

12. О применении судами общей юрисдикции общепризнанных принципов и норм международного права и международных договоров Российской Федерации: постановление Пленума Верховного Суда РФ от 10 окт. 2003 г. № 5 (с изм. от 5 марта 2013 г.) // Российская газета. 2003. 2 дек. Федер. вып. № 0(3358).

13. О применении судами общей юрисдикции Конвенции о защите прав человека и основных свобод от 4 ноября 1950 года и Протоколов к ней: постановление Пленума Верховного Суда Российской Федерации от 27 июня 2013 г. № 21 // Российская газета. 2013. 5 июля. Федер. вып. № 145(6121).

14. Anatoly I. Kovler. European Convention on Human Rights in Russia // Dans L'Europe en Formation. 2014/4 (№ 374). P. 116-135.

15. Дело «Штукатуров (Shtukaturov) против Российской Федерации» (жалоба № 44009 / 05): постановление Европейского суда по правам человека от 27 марта 2008 г. [Электронный ресурс]. Доступ из СПС «КонсультантПлюс».

16. О внесении изменений в главы 1, 2, 3 и 4 части первой Гражданского кодекса 
Российской Федерации: Федер. закон от 30 дек. 2012 г. № 302-Ф3 (с изм. от 4 марта 2013 г.) // Российская газета. 2013. 11 янв. Федер. вып. № 3(5979).

17. Доклад о результатах мониторинга правоприменения в Российской Федерации за 2019 г. URL: https://minjust.gov.ru/uploaded/files/doklad_qcmZYtl.pdf

18. Доклады о результатах мониторинга правоприменения в Российской Федерации за 2011-2019 гг. URL: https://minjust.gov.ru/ru/pages/doklady-prezidentu-rossijskojfederacii-o-rezultatah-monitoringa-pravoprimeneniya/

19. Abramova $M$. Constitutional Justice of Russia within the judicial landscape of contemporary Europe. URL: https://www.researchgate.net/publication/321788102_Constitutional_Justice_of_Russia_within_the_judicial_landscape_of_contemporary_Europe

20. Велиева Д.С., Пресняков М.В. Исполнение решений ЕСПЧ: национальные демократические процедуры vs правовая определенность // Вестник Поволжского института управления. 2020. Т. 20, № 6. С. 10-27.

21. По делу о проверке конституционности положений статей 16, 20, 112, 336, 376, 377, 380, 381, 382, 383, 387, 388 и 389 Гражданского процессуального кодекса Российской Федерации в связи с запросом Кабинета министров Республики Татарстан, жалобами открытых акционерных обществ «Нижнекамскнефтехим» и «Хакасэнерго», а также жалобами ряда граждан: постановление Конституционного Суда РФ от 5 февр. 2007 г. № 2-П. URL: http://www.consultant.ru/document/cons_doc_LAW_66124/

22. О внесении изменений в Федеральный конституционный закон «О Конституционном Суде Российской Федерации»: Федер. конституционный закон от 14 дек. 2015 г. № 7-ФКЗ // Российская газета. 2015. 16 дек. Федер. вып. № 284(6855).

23. Бланкенагель $A$. Европейский суд по правам человека против российского Конституционного Суда: о нормальных трениях, скрытых угрозах и предвзятой близорукости // Закон. 2019. № 6. С. 52-60. 